\title{
“TI por Elas": para Mulheres que estão Dentro e Fora da Computação
}

\section{Bárbara Stéphanie Neves Oliveira ${ }^{1}$, Joyce Nayne Araújo Nascimento ${ }^{1}$, Maria Tassiane Barros de Lima ${ }^{1}$, Nayara Maria Costa de Mesquita ${ }^{1}$, Carla Ilane Moreira Bezerra ${ }^{1}$, Paulo de Tarso Guerra Oliveira ${ }^{1}$}

\author{
${ }^{1}$ Campus Quixadá - Universidade Federal do Ceará (UFC) \\ Quixadá - CE - Brasil \\ \{barbara.steph, tassiane, jnas\}ealu.ufc.br, \\ \{nayaramesquit, carlailane\}@gmail.com, \\ paulodetarsoeufc.br
}

\begin{abstract}
This paper describes the activities developed by the "IT for Them (Girls)" action, which is organized by the Academic Center of Computer Science in partnership with the Education Program Tutorial of Information Technology - Knowledge Connections in the Federal University of Ceará - Quixadá Campus. The main objective of the action is to cultivate the interest of women in the field of Information Technology (IT) as well as disseminating what computer science is and your importance. In view of the public of this field, the present action is also intended to help reduce the evasion of women who already belong to IT.
\end{abstract}

Resumo. Este artigo descreve as atividades desenvolvidas pela ação "TI por Elas”, que é organizada pelo Centro Acadêmico de Ciência da Computação (CACC) em parceria com o Programa de Educação Tutorial/Conexões de Saberes (PET - TI) do Campus da UFC em Quixadá. Essa ação tem como objetivo principal cultivar o interesse de mulheres pela área da Tecnologia da Informação (TI), tanto como disseminar o que é a computação e sua importância. Tendo em vista o público da área, a presente ação também pretende ajudar a diminuir a evasão das mulheres que já se encontram no âmbito da TI.

\section{Introdução: Por que mais mulheres?}

Historicamente, a Ciência como um todo vem sendo caracterizada por se tratar de uma atividade predominantemente masculina. Desde a Segunda Guerra Mundial até a década de 1960, foram poucos os trabalhos de mulheres que receberam destaque no setor informático. Além disso, também é baixa a proporção de estudantes mulheres que estão presentes nos cursos ligados às áreas de Tecnologia da Informação (TI) [Moreira et al. 2014].

Temos hoje uma ideia estereotipada de que mulheres não possuem competência ou habilidade para estudar e atuar nestes ramos, mas, sabemos que essa ideia é bem equivocada se comparada à realidade: estudos comprovam que equipes mistas desenvolvem trabalho mais eficiente na computação, pois mulheres e homens se preocupam com aspectos diferentes de um produto. Ademais, a falta de qualquer tipo de incentivo ou conhecimento fazem com que muitas garotas acabem seguindo campos que são tradicionalmente considerados femininos. Portanto, quando perguntadas sobre quais profissões pretendem 
exercer, dificilmente consideram a área de Computação ou alguma outra proveniente das Ciências Exatas [Moreira et al. 2014].

Além das dificuldades quanto ao meio acadêmico, ainda há agravantes como o preconceito e salários menores. O Índice de Desigualdade de Gênero (IDG) retrata as diferenças de oportunidades levando em consideração os seguintes quesitos: saúde reprodutiva, empoderamento (autonomia) e atividade econômica. A desigualdade na atividade econômica é medida pela participação de homens e mulheres no mercado de trabalho. $\mathrm{O}$ Brasil ocupa a $92^{a}$ posição em uma lista de 159 países segundo o IDG [PNUD 2017]. A média de anos de escolaridade entre as mulheres é de 8,1 e de homens, de 7,5. Porém, mesmo que a escolaridade das mulheres seja mais elevada, a renda per capita é maior entre homens [PNUD 2017].

O ingresso de mulheres na área de TI ajuda a quebrar paradigmas. Assim, a promoção da área é uma ação fundamental. Essa divulgação deve consistir de ações que motivem e consequentemente despertem interesse. O Programa Meninas Digitais, associado a SBC (Sociedade Brasileira de Computação), por exemplo, tem como objetivo apresentar a área como possível meio para realização profissional, motivando alunas concludentes do Ensino Fundamental, Ensino Médio e Ensino Tecnológico a seguirem carreira nas áreas da computação [Maciel and Bim 2017]. Um modo de alcançar esse propósito é apresentar experiências de mulheres que integram e colaboram no enfrentamento da desigualdade existente na área de TI.

Este artigo tem como objetivo apresentar a ação "TI por Elas", realizada por alunas da Universidade Federal do Ceará (UFC) - Campus Quixadá. A principal meta da ação é quebrar os paradigmas de gênero existentes, principalmente nos meios acadêmico e tecnológico, compostos em sua maioria por homens.

\section{A História: "TI por Elas"}

Com o objetivo de desmistificar a ideia de que mulheres são despreparadas para tecnologia, bolsistas do Programa de Educação Tutorial/Conexões de Saberes (PET - TI da UFC - Campus Quixadá), idealizaram e realizaram um evento denominado InfoGirl, baseado em um acampamento de programação realizado na Universidade de Stanford (Stanford University - Leland Stanford Junior University) ${ }^{1}$, cujo foco era atrair mulheres para a computação e mostrar que a TI pode ser explorada por qualquer pessoa, independente do seu sexo.

A primeira edição do InfoGirl ocorreu em 2014, tendo como público-alvo meninas do Ensino Médio. Desde a edição de 2016, o InfoGirl conta com o apoio do Centro Acadêmico de Ciência da Computação (CACC da UFC - Campus Quixadá), além de outras colaborações. $\mathrm{Na} 3^{\text {a }}$ edição do evento, foi desenvolvida e aplicada uma nova ação chamada "TI por Elas". Essa ação foi inspirada na atividade Birds of Feather do evento Micwic (Michigan Women in Computer Science) realizada pela Universidade Estadual de Michigan (Michigan State University) ${ }^{2}$. Seu principal objetivo consiste em promover um

\footnotetext{
${ }^{1}$ A Universidade Stanford é uma universidade privada estadunidense de pesquisa situada em Palo Alto, Califórnia, e uma das instituições mais prestigiadas do mundo, com a maior seletividade de graduação e a posição de primeira colocada em várias pesquisas e medições nos Estados Unidos.

${ }^{2}$ Universidade Estadual de Michigan é uma universidade pública norte-americana localizada na cidade de East Lansing, no estado de Michigan.
} 
ambiente cordial por meio de rodas de conversas informais, onde as participantes podem esclarecer suas dúvidas nos mais diversos assuntos, sobre a área da computação, mercado de trabalho, e até mesmo experiências de vida, pelo relato das profissionais participantes.

Após três edições de completo sucesso, almeja-se alcançar um grande número de garotas e atraí-las para computação. A ação busca assim contribuir com a formação das participantes, para que estas possam se sentir confiantes e familiarizadas com mais esta opção para quando forem decidir suas carreiras, como também pretende fortalecer o vínculo das alunas e professoras do Campus, de modo a trocar experiências e tentar reduzir a evasão de mulheres nos cursos de TI.

\section{Momento "TI por Elas"}

Em sua primeira edição, o "TI por Elas" foi organizado na seguinte dinâmica de ação onde foram montados 5 (cinco) grupos temáticos: (i) Mercado na TI; (ii) Graduação; (iii) Vida universitária; (iv) Computação no dia a dia; e, (v) Experiência no exterior. Esses grupos eram coordenados por professoras e universitárias que dividiam as participantes entre eles. Em períodos de tempo determinados (20 minutos), elas eram rotacionadas entre os grupos para que todas pudessem ter conhecimento dos temas.

Também foram sugeridos para as professoras tópicos de conversas: perguntas que elas poderiam responder antes mesmo de gerar curiosidades nas alunas de Ensino Médio, de acordo com os temas propostos. Após essa conversa inicial, as professoras esclareciam e discutiam as questões geradas pelas participantes.

Algumas das principais perguntas feitas nos grupos foram: "Existe um perfil para ingressar em uma graduação de TI?", "Quais os conteúdos básicos abordados em toda graduação de TI?", “Como é sair de casa e estudar fora?", "Qual a rotina, ou o que uma profissional de TI geralmente faz no seu dia a dia de trabalho?", e "Como é morar fora do país?, Quais os desafios?”.

Durante a edição de 2016, identificou-se a necessidade de não só trazer meninas para o campo da computação, como também manter o interesse das que já estão. Visando isso, após a repercussão do "TI por Elas", foi considerada a ideia de que esse momento deveria fazer parte de alguma atividade a ser aplicada no Campus Quixadá da UFC, como uma ação de afirmação e de incentivo a permanência de alunas nos cursos.

Em Julho de 2017 foi realizada a primeira sessão do "TI por Elas" no Campus. Ele foi organizado pelas garotas do CACC e do PET - TI. O projeto foi concebido com a intenção de ser realizado pelo menos uma vez por semestre, possuindo um formato semelhante ao de uma reunião informal entre as mulheres que estudam ou trabalham na instituição, não só professoras, mas também servidoras, que durante as sessões relatam suas experiências e ficam disponíveis a responder dúvidas. Todas as alunas, independente de curso ou semestre, podem participar, tirar suas dúvidas e, assim, encurtar relações.

A principal diferença do "TI por Elas" que acontece no Campus para o que acontece no InfoGirl, é que existe apenas um grupo formado com as participantes, com assuntos que variam de acordo com as propostas feitas pelas alunas e professoras. Em sua primeira edição ocorreu uma apresentação geral, onde professoras falaram sobre suas trajetórias e alunas expressaram os motivos que as levaram a escolher a área da computação. Em seguida, foram apresentadas às professoras, questões teóricas sobre mercado de tra- 
balho, história acadêmica, além de questões práticas sobre como é estudar/trabalhar no exterior.

\section{Resultados da Ação}

As sessões do "TI por Elas" forneceram variados resultados, mas com duas perspectivas diferentes: uma voltada para estudantes do Ensino Médio e outra para alunas universitárias. Durante a primeira ação feita no InfoGirl, foi notado entusiasmo pelas participantes quando as mesmas se sentiram confortáveis o suficiente com o modo que a conversa fluía com as professoras, visto que a área de TI lhes foi apresentada com uma nova visão, feita por mulheres bem sucedidas na área.

Algumas das participantes relataram que ainda não sabiam qual graduação cursar, e que agora estavam pretendendo ingressar em TI para descobrir ainda mais sobre o que lhes foi apresentado. Outras não demonstraram interesse, o que também é um resultado positivo, pois não irão iniciar uma graduação que não estimam.

Já no final da segunda sessão que ocorreu no Campus, durante o coffee break, foram formados pequenos grupos onde alunas fizeram perguntas bem específicas às professoras, as quais talvez não se sentiram confiantes para fazer durante as apresentações iniciais. Algumas dessas perguntas foram de alunas que estavam se formando e não sabiam que rumo seguir depois de concluir a graduação. Foi também notado a presença de calouras, como também veteranas curiosas a respeito da ideia causada pela movimentação.

Contudo, alguns pontos em comum podem ser notados nesses dois momentos: incerteza, tanto por parte das estudantes do Ensino Médio que se sentem pressionadas por seus futuros, quanto por parte das discentes não convencidas antes sobre o que cursar e nem se ainda irão continuar; autossabotagem, pois a falta de confiança pessoal aumenta essa incerteza na escolha de carreira ou em permanecer, mesmo que já se sintam familiarizadas; e, medo de arriscar, já que a área em boa parte é composta por homens.

\section{Conclusões Finais}

Como citado na seção anterior, com as iniciativas do "TI por Elas", foi analisado que um maior número de meninas sentem vontade de ingressar na área de TI. Em relação às garotas que já estão no ramo, a ação visa reduzir a evasão, além de mostrar união e acolhimento. Para a melhoria do fluxo informacional desse movimento, ainda torna-se necessário um reconhecimento por parte de estudantes da universidade, que muitas vezes não se interessam ou não são notificados de tais atividades, e, da sociedade, pois este tipo de ação é fundamental para mudanças e melhorias em relação às questões de gênero. Inclusive, em 2017 foi realizada a primeira edição do "TI por Elas" dentro da programação dos Encontros Universitários (EU) da UFC, pois é necessário desenvolver essas ações constantes que possibilitem uma maior inclusão de mulheres [Moreira et al. 2014].

\section{Referências}

Maciel, C. and Bim, S. A. (2017). Programa Meninas Digitais - ações para divulgar a Computação para meninas do ensino médio. Anais do Computer on the Beach, pages 327-336.

Moreira, J. A., de Oliveira Mattos, G., and Reis, L. (2014). Um Panorama da Presença Feminina na Ciência da Computação. In $18^{\circ}$ REDOR. 
PNUD (2017). Relatório de Desenvolvimento Humano 2016: Desenvolvimento Humano para Todos. Estocolmo, Suécia. 